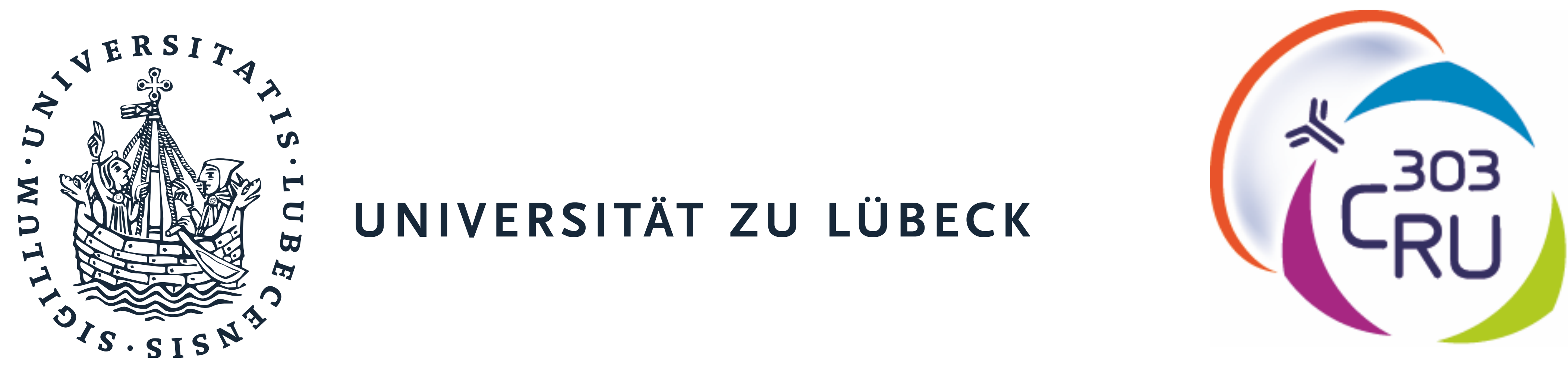

\title{
12/15-lipoxygenase counteracts and resolves pemphigoid disease-like dermatitis
}

Tanya Sezin ${ }^{1}$, Nerea Ferreirós ${ }^{2}$, Claudia Attah ${ }^{1}$, Khoroljav Ochirbold ${ }^{1}$, Sadegh Mousavi ${ }^{1}$, Detlef Zillikens ${ }^{1}$, Gerd Geisslinger ${ }^{2}$, Christian D. Sadik

${ }^{2}$ pharmazentrum frankfurt/ZAFES, Institute of Clinical Pharmacology, Johann-Wolfgang-Goethe-Universität Frankfurt, Frankfurt am Main, Germany

\section{Introduction}

- A novel paradigm suggests that the termination of acute tissue inflammation and the restoration of tissue homeostasis is an active and tightly regulated process called "resolution". As a corollary, chronic inflammation may emerge from delayed or failing resolution.

- A diverse class of lipid mediators has been suggested to orchestrate resolution. The enzyme 12/15-lipoxygenase (12/15-LO) is involved in the biosynthesis of many of these specialized pro-resolving lipid mediators (SPMs).

- With most studies on resolution investigating acute peritonitis or acute lung inflammation, the validity of this concept for skin inflammation is uncertain.

- Here, we explored the impact of 12/15-LO activity on the course of pemphigoid disease-like dermatitis.

\section{Results}

12/15-LO deficient $\left(A / O \times 15^{-/}\right)$mice exhibit impaired resolution of antibody transfer EBA
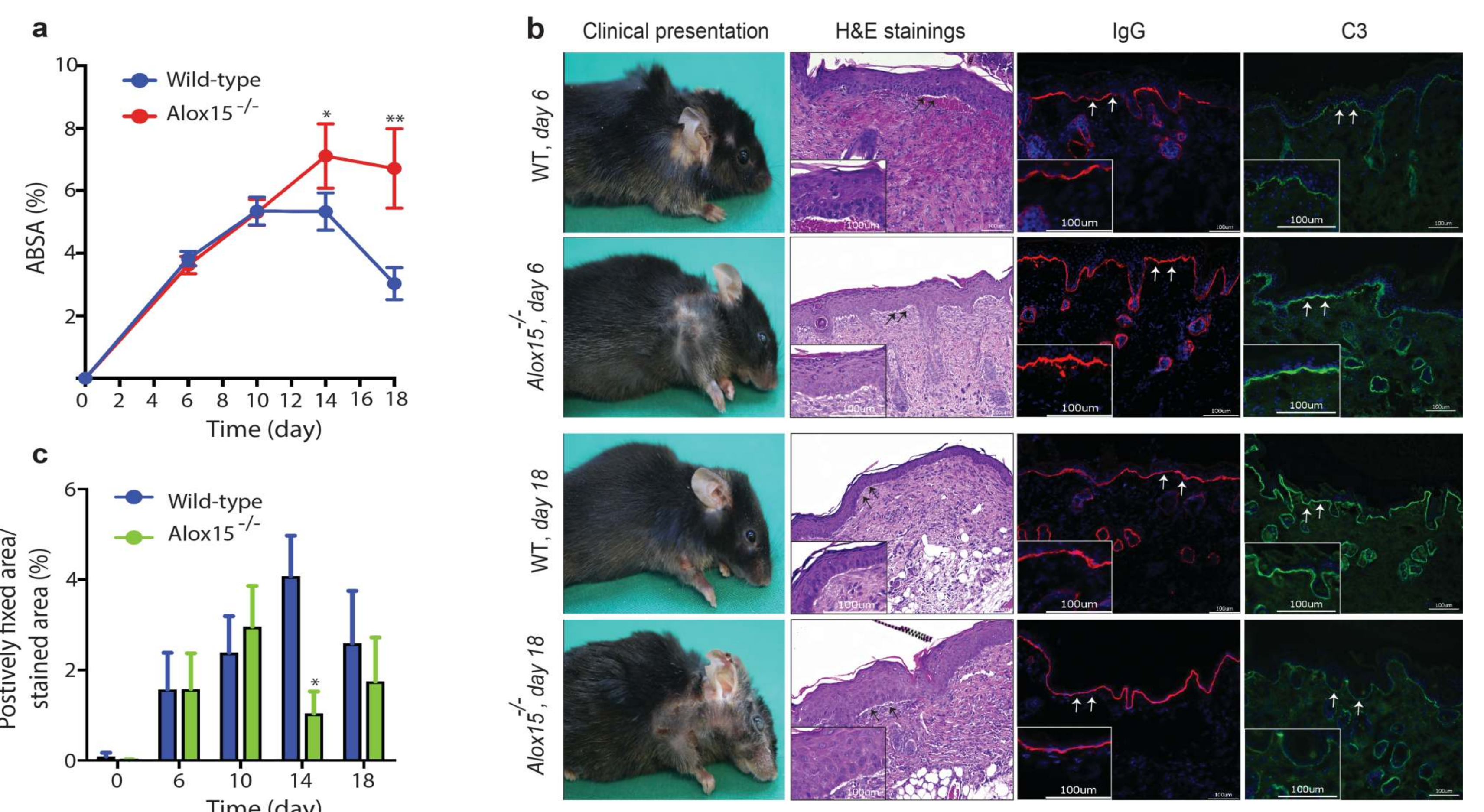

Figure 1. Alox $15 \cdot$ mice exhibit impaired resolution of antibody transfer BP-like EBA. (a) Clinical severity of antibody-transfer EBA
in wild-type vs. Alox $15-\cdots$ mice was assessed. Mice were harvested on days $6,10,14$, and 18 and skin samples were obtained.

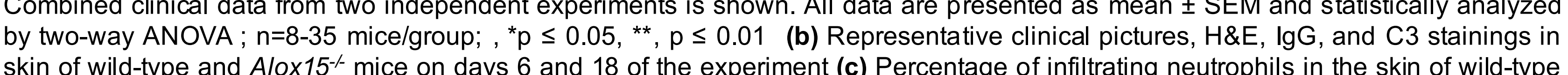
and Alox 15 - mice throughout the course of the disease is

12/15-LO expression is expressed in a subpopulation of PMNs in the dermis of pemphigoid disease-like skin lesions

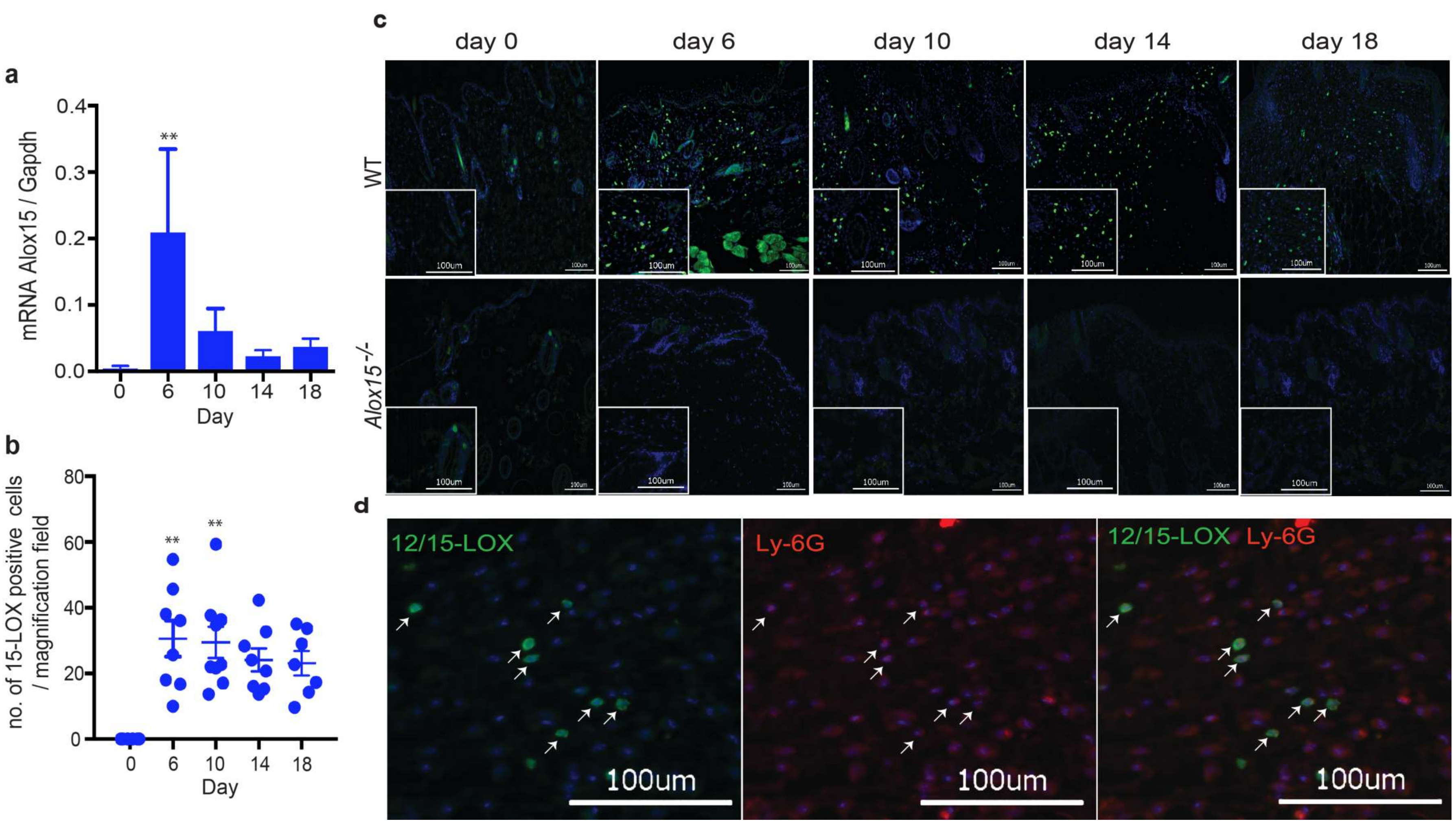

Figure 2. 12/15-LO expression is upregulated upon antibody-transfer EBA and is specifically expressed in PMN.
(a-b) Quantification of 12/15-LO expression in skin of wild-type mice following induction of antibody-transfer EBA as de PCR and IHC, respectively. (c) Repressentative IHC pictures of perilesional skin sections stained with anti-12/15-LO antibody (green) and DAPI (blue) (d) In murine skin, 12/15-LO is exclusively expressed on infiltrating PMN as demonstrated by dual IF staining with anti-12/115-
LO antibody (green), neutrophil-specific anti-Ly-6G antibody(red), and DAPI (blue). Combined data from two independent experiments is sown. All data are presented as mean \pm SEM and were analyzed w
Elevated levels of DHA-derived SPMs are present in lesional skin of wild-type, but not in skin of Alox $15^{-/-}$mice

\begin{tabular}{|c|c|c|c|c|}
\hline & $\begin{array}{c}\text { Time atter I } 196 \\
\text { injection }\end{array}$ & 10,17 -DHDHA & $17 \mathrm{~s}$ HDHA & $145 \mathrm{HDHA}$ \\
\hline WT & $\begin{array}{l}0 \\
6 \\
10 \\
14\end{array}$ & $\begin{array}{c}\text { n.d. } \\
10.70 \pm 6.99 \\
6.66 \pm 2.42 \\
\text { n.d. }\end{array}$ & $\begin{array}{l}131.75 \pm 27.50 \\
>>10 Q \\
383.71 \pm 2.51 \\
>\text { >LOOQ }\end{array}$ & $\begin{array}{c}212.29 \pm 411.98 \\
>>U L O Q \\
>\text { PLOQ } \\
>\text { >ULOQ }\end{array}$ \\
\hline Alox $\times 15^{4}$ & $\begin{array}{l}0 \\
6 \\
10 \\
14 \\
18\end{array}$ & $\begin{array}{c}\text { no.d. } \\
1.38 \pm 0.48 \\
1.650 .11 \\
\text { n.d. } \\
\text { nd. }\end{array}$ & 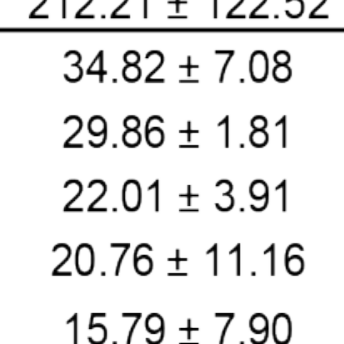 & 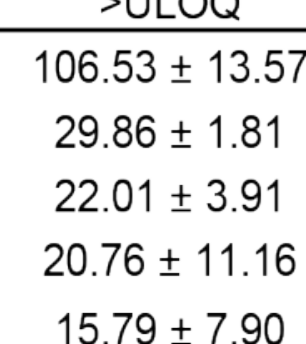 \\
\hline
\end{tabular}

Figure 3. Elevated levels of 10,17-DiHDHA, 17S-DHDA, and 14S-DHDA are present in lesional skin of WT mice, but not
in skin of Alox $15 \%$ mice. The expression of SPMS in skin of wild-type and Alox $15 \%$ mice was determined. Dorsal skin

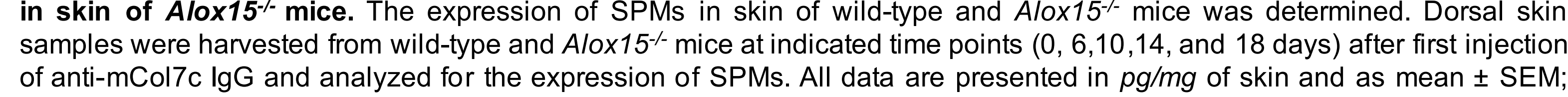

Alox15\%- PMN show altered morphology and effector functions in comparison to WT PMN

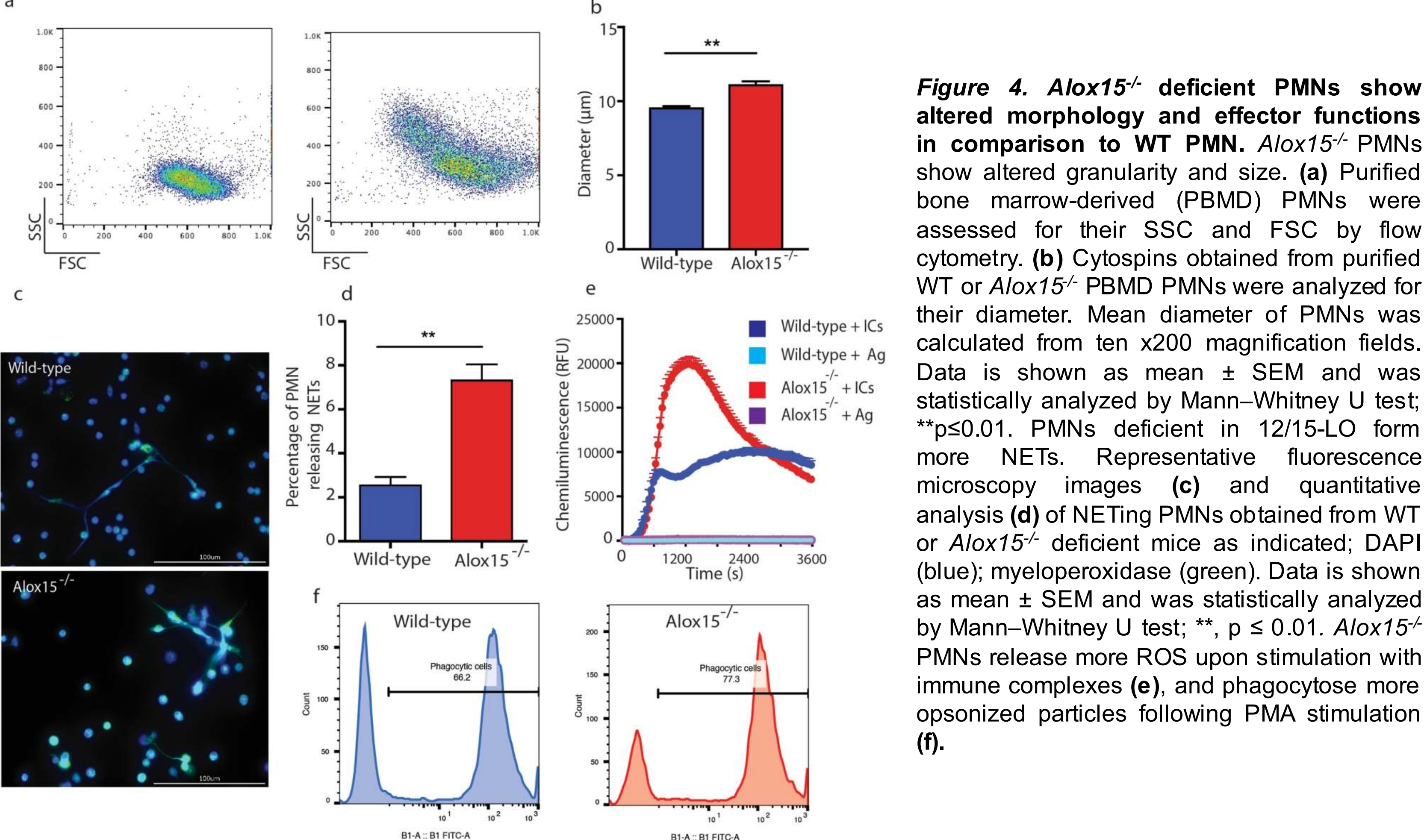

\section{Conclusions}

12/15-LO counteracts pemphigoid disease-like dermatitis and ensures its timely resolution via the biosynthesis of SPMs

- 12/15-LO curbs neutrophil activation.

- The enzyme is specifically induced in subpopulation of PMNs infiltrating the skin, hinting at PMNs as orchestrators of the termination of dermatitis.

Promoting 12/15-LO expression or pharmacologically mimicking its effects may offer a novel therapeutic strategy in the treatment of pemphigoid diseases.

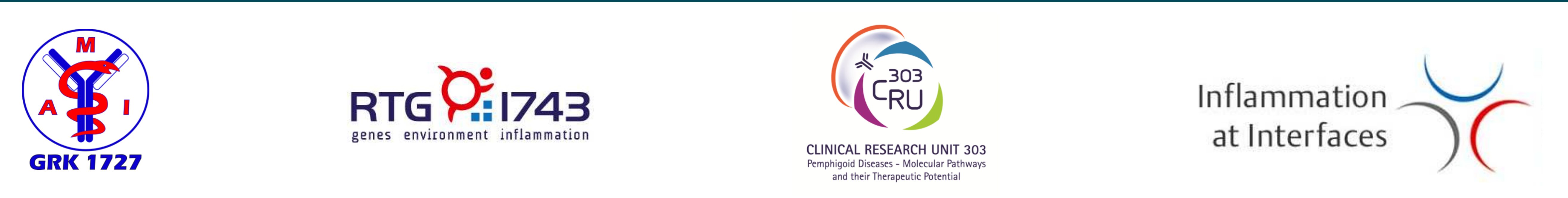

